\title{
Experimental Study on the Dynamic Response of Polyurethane/fly Ash Ceramic Foam
}

\author{
ADRIAN ROTARIU ${ }^{1}$, EUGEN TRANA ${ }^{1}$, LIVIU MATACHE ${ }^{1}$, \\ MARIUS-VALERIU CIRMACI-MATEI ${ }^{1}$, SIMONA SANDU ${ }^{2}$, \\ CRISTIAN-EMIL MOLDOVEANU ${ }^{1}$, FLORINA BUCUR ${ }^{1 *}$ \\ ${ }^{1}$ Military Technical Academy Ferdinand I, 39-49 G. Cosbuc Av., 040531, Bucharest, Romania \\ ${ }^{2}$ Scientific Research Center for CBRN Defense and Ecology, 225 Oltenitei Road, 041309, Bucharest, Romania
}

\begin{abstract}
Nowadays, the investigation of both classic and new materials for blast mitigation applications is a subject intensively approached in the scientific literature. Due to their mechanical behavior, the polyurethane foams are materials with high potential for this type of applications. Within the current paper a EUROPLASTIC® polyurethane foam grade mixed with fly ash ceramic micro powder was experimentally investigated. Using a single stage gas gun, the dynamic response of polyurethanelfly ash ceramic foam was thoroughly evaluated in terms of specific stress vs volumetric strain curves response and dissipated kinetic energy, also.
\end{abstract}

Keywords: polyurethane foam, mechanical behavior, dynamic load

\section{Introduction}

In the last decades almost all the proposed blast attenuation solutions included the use of energyabsorbing or energy-dissipating materials. Thereby, the scientific studies related with this particular topic were focused on identifying effective mechanisms for blast energy dissipation and impulse attenuation [1-4].

Several studies related with blast attenuation applications pointed out that the energy dissipation process is closely related with the material volumetric strain capacity [5-11].

The materials able to tolerate consistent volumetric strain may be divided in two categories [10]: elastoplastic materials with a distinct yield point and plastic-elastic materials with no distinct yield point. Among elastoplastic materials lies polyurethane foam, also. Especially, the layered configurations of polyurethane foam are of great interest when one refers to impulse attenuation capacity.

The distinct behavior of the crushable foam during a blast-loading application that implies a large loaded area, namely the foam layer can be considered laterally confined and the only displacement that occur is in the loading direction, makes this specific material type suitable for blast mitigation applications. In fact, considering the assumption of lateral restraint, the specific behavior closely related with the energy-dissipating capability of foams can graphically highlighted as in Figure 1 and Figure 2 [11].

In line with the previously presented considerations, the present paper aims to experimentally investigate the behavior of an elastoplastic material namely a polyurethane foam mixed with fly ash ceramic micro powder, dynamically axial loaded in compression.

The experimental investigation looked into the specific stress vs volumetric strain foam type material response and highlighted its specific ability to dissipate kinetic energy.

For experimental tests a single stage gas gun was used. The cylindrical specimens were made from a EUROPLASTIC $®$ closed cell polyurethane foam. A high-speed camera for image recording was used, also.

\footnotetext{
*email: florina.bucur@mta.ro
} 


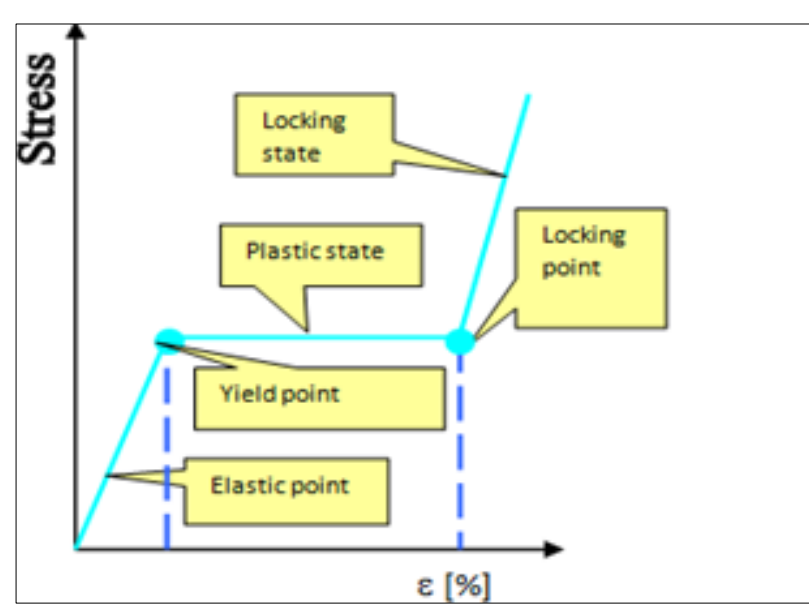

Figure 1. Stress-strain relations for an elastoplastic material (liniar-plastic-liniar) [11]

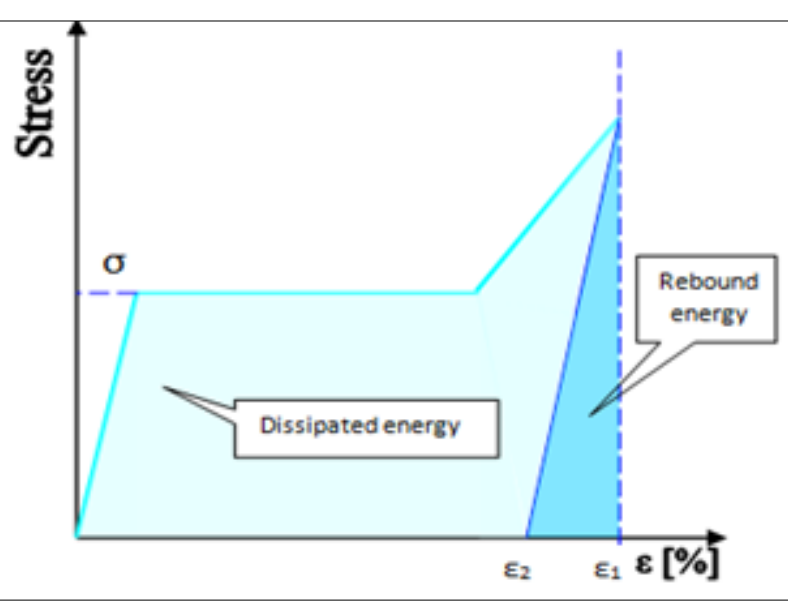

Figure 2. Dissipated energy and rebound energy for an ideal elastoplastic material [11]

\section{Materials and methods}

\subsection{Material and specimen types}

For polyurethane foam specimens manufacturing process, a polymeric matrix (Purex WG 3035®, Suprasec 5005®) was mixed with fly ash, a low cost ceramic micro powder.

Fly ash micro powder consists primarily of silicon oxides, aluminum iron and calcium. The color can be tan to dark gray, depending on its chemical and mineral constituents.

The silt-sized particles which are generally spherical, typically ranging in size between 10 and 100 microns improve the fluidity and workability of polyurethane foam [12].

Three types of specimens with different densities were proposed for the experimental study.

The polyurethane closed cell foam plates were produced by EUROPLASTIC Company. From the plates provided by the manufacturer, of different thicknesses and densities, several samples have been processed. Specimen's dimensions and relevant physical properties are presented in Table 1.

Table 1. Specimen's dimensions and relevant physical properties

\begin{tabular}{|c|c|c|c|c|c|}
\hline & Sample diameter $(\mathrm{mm})$ & Height $(\mathrm{mm})$ & Mass $(\mathrm{g})$ & Volume $\left(\mathrm{cm}^{3}\right)$ & Density $\left(\mathrm{g} / \mathrm{cm}^{3}\right)$ \\
\hline C1 & 46.00 & 24.40 & 2.36 & 40.52 & 0.058 \\
\hline C2 & 46.70 & 19.80 & 2.00 & 33.89 & 0.059 \\
\hline C3 & 50.10 & 20.00 & 2.22 & 39.4 & 0.056 \\
\hline
\end{tabular}

\subsection{Experimental set-up}

The experimental testing procedure was designed to evaluate the polyurethane foam response to dynamically uniaxial compression load. The load on the samples was applied on the foams' rise direction.

For the polyurethane foam dynamic tests, a single stage gas gun was used. By this approach different impact velocities were able to be set.

The experimental set-up is presented in Figure 3. 


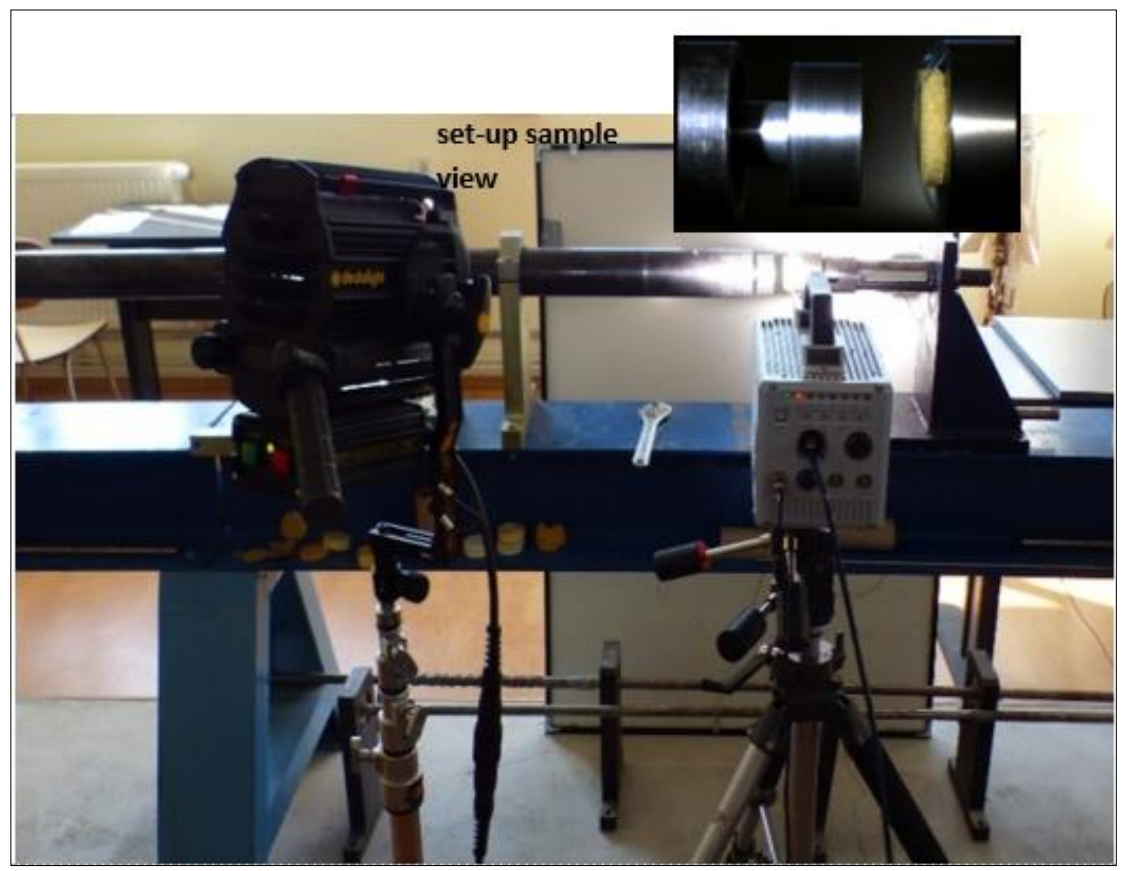

Figure 3. Experimental set-up

For force history recordings a PCB Piezotronics 200B05 force transducer along with a PCB signal conditioner and a 4xxx PicoScope series were considered. The 200B05 force transducer was attached to a rigid steel support. The polyurethane foam specimen was attached to a cylindrical support in the front of barrel muzzle with adhesive tape.

The even loading of specimen on impact was assured by the use of 1.11 kilograms aluminum flat end projectile.

A high speed PHOTRON camera with 25,000 fps setting was used for experimental tests recording.

\section{Results and discussions}

The tests recorded images along with force data recordings and post-test samples measurements were used for stress vs volumetric strain analysis. A typical time history of recorded force signal is depicted in Figure 4.

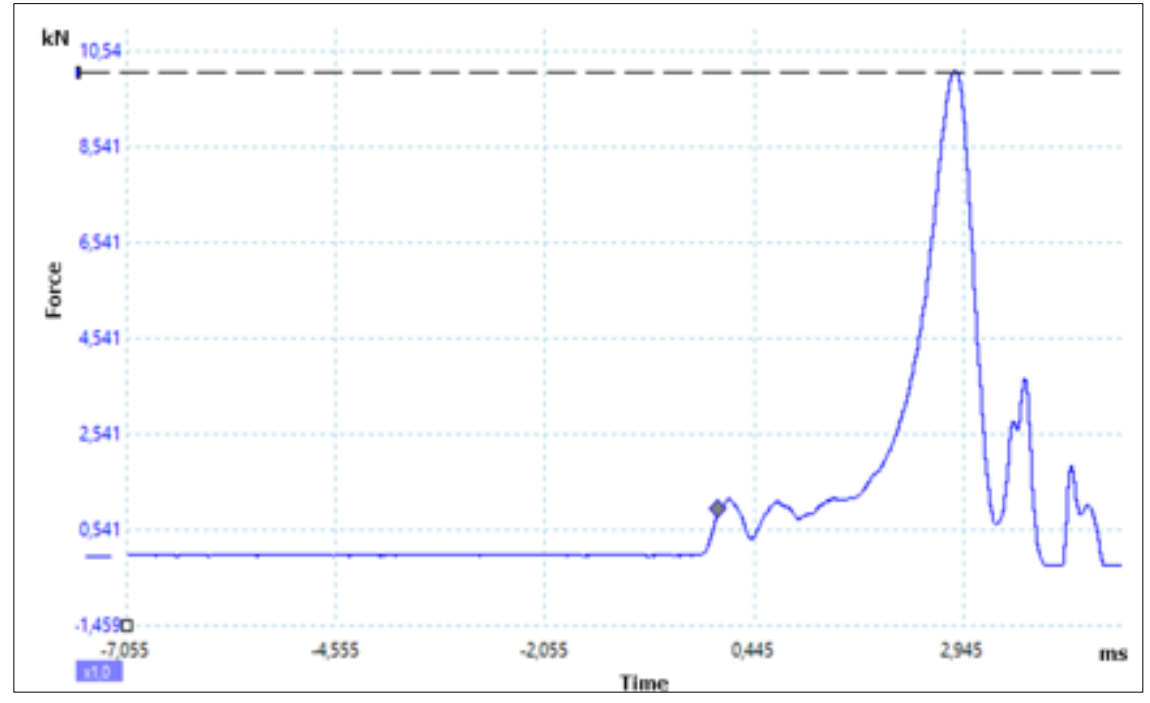

Figure 4. Typical example of force vs time signal 
A number of 6 tests were performed. The data related with post-test sample measurements are recorded in Table 2.

Table 2. Post-test measured dimensions

\begin{tabular}{|c|c|c|}
\hline Sample type & $\begin{array}{c}\text { Post-test diameter } \\
(\mathrm{mm})\end{array}$ & $\begin{array}{c}\text { Post-test height } \\
(\mathrm{mm})\end{array}$ \\
\hline C1 & 48.70 & 9.10 \\
\hline \multirow{2}{*}{ C2 } & 48.20 & 10.00 \\
\cline { 2 - 3 } & 49.00 & 7.20 \\
\hline \multirow{3}{*}{ C3 } & 53.50 & 9.20 \\
\cline { 2 - 3 } & 53.70 & 8.60 \\
\cline { 2 - 3 } & 53.70 & 8.00 \\
\hline
\end{tabular}

Using the recorded Photron images and special tracking software, the projectile velocity and acceleration were investigated. However, due to the fact that the used velocity tracking methodology is highly dependent of pixel dimension, the curves determined by this method were affected by the image quality. Thereby, the raw data are oscillating nature signals. In order to make the data useful a filtering algorithm was used allowing impact and rebound velocity readings. The graphs for unfiltered and filtered velocity are depicted in Figure 5.

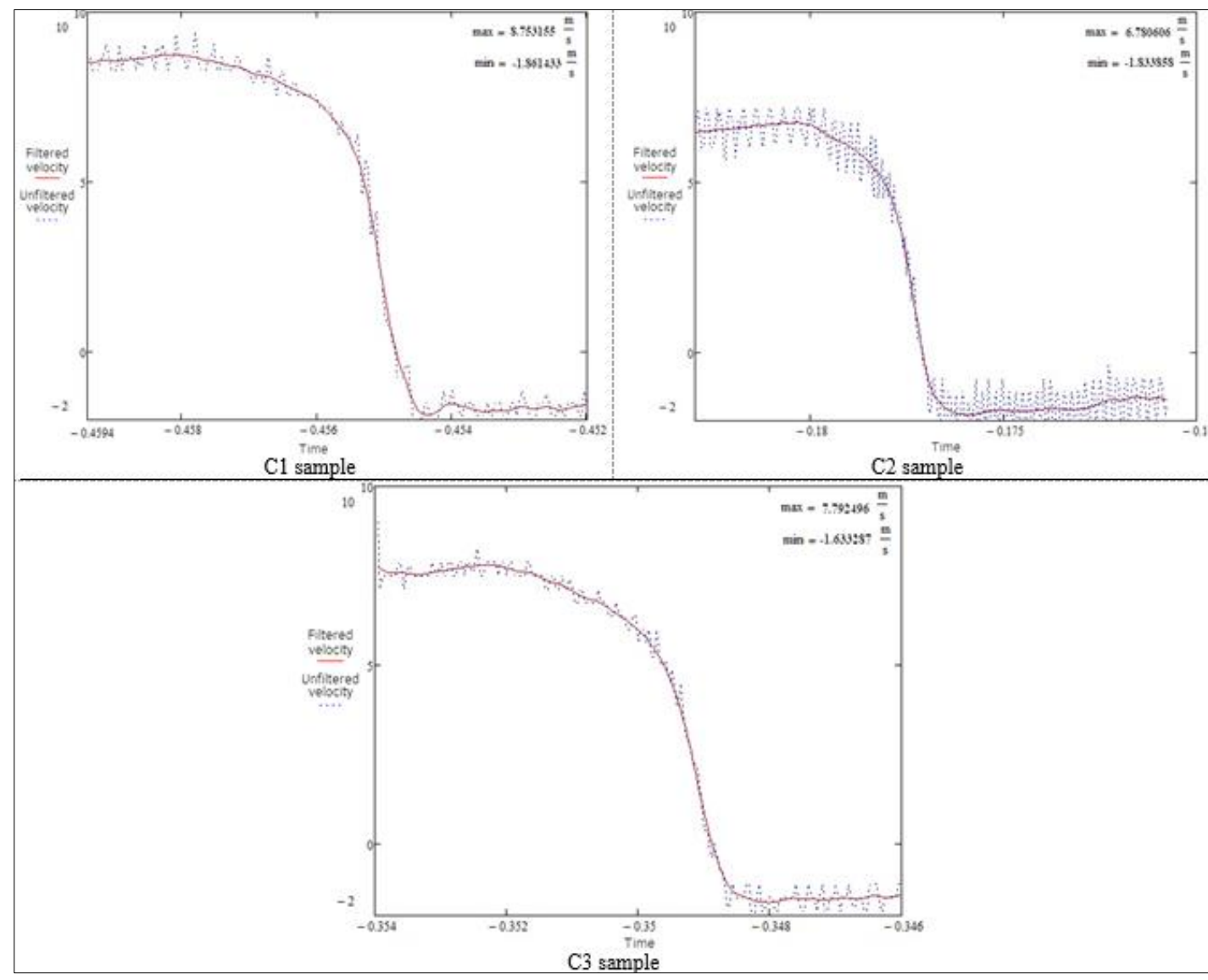

Figure 5. Evolution of the projectile velocity

Based on projectile mass value and conservation momentum law the video recorded data were processed to determine the force that acts on the projectile.

The force vs time history based on image processing $\left(\mathrm{F}_{\mathrm{img}}\right)$ and the one recorded by the use of force transducer $\left(\mathrm{F}_{\text {trad }}\right)$ are compare against each other in Figure 6. 

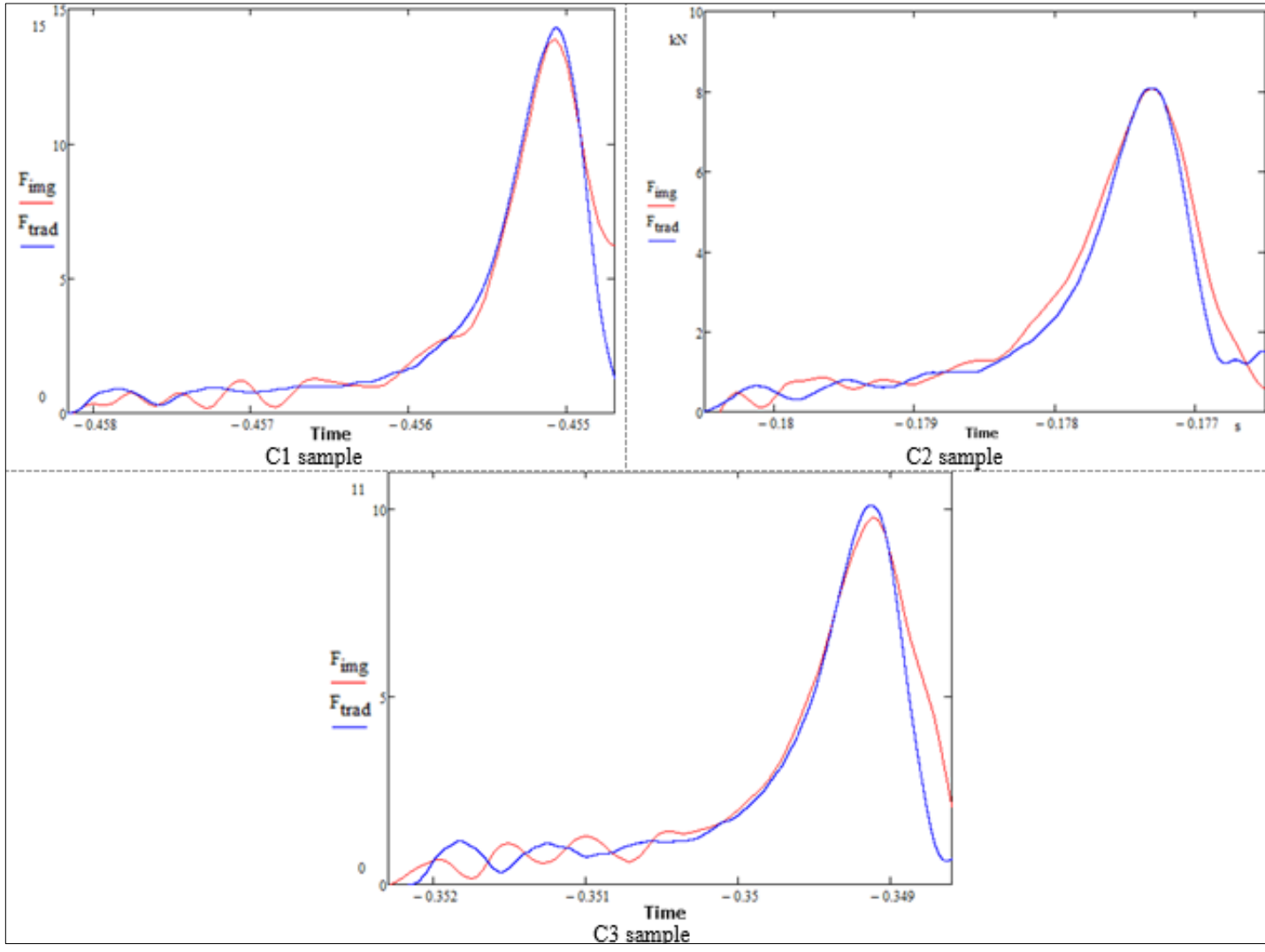

Figure 6. Image based data vs recorded transducer data

By pairing the impact velocity data and force history, the specific stress and volumetric strain can be determined. A typical stress vs volumetric strain curve is indicated in Figura 7.

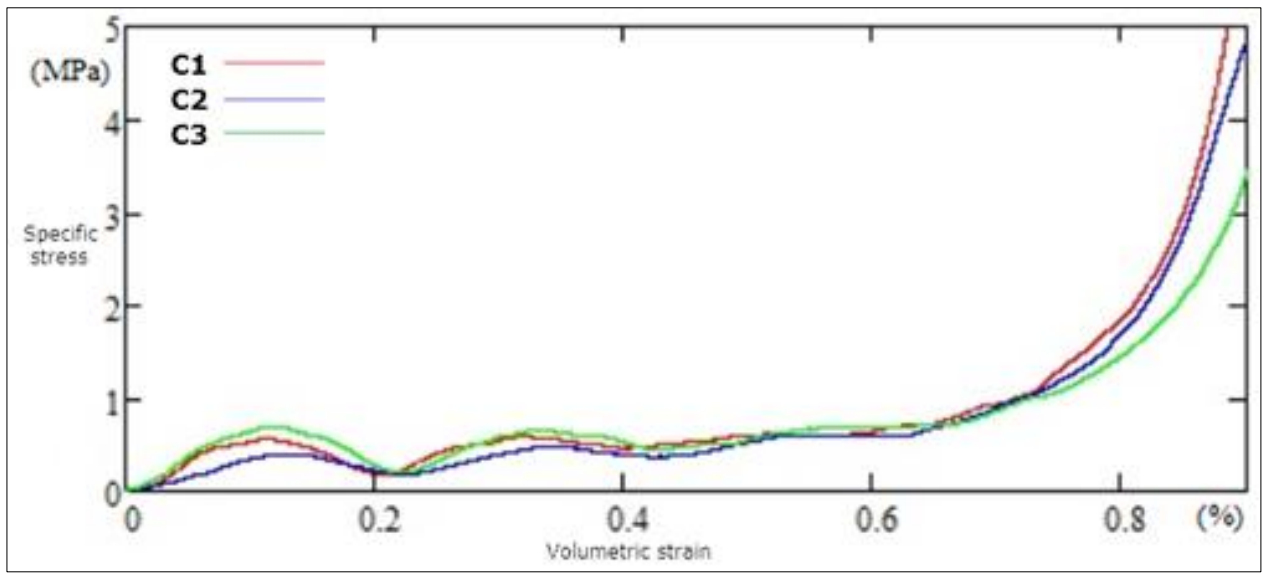

Figure 7. Specific stress vs volumetric strain

The processed data indicates the existence of yielding. The curves thus determined are also characterized by a series of oscillations before the densification point occurrence.

The above-mentioned oscillations are not related to the specific constitutive law of polyurethane foam. The reason of oscillations occurrence is the dynamic loading of specimen and the chosen measurement method.

In addition to stress vs volumetric strain curves, an extensive data analysis which combined the force signal analysis, image processing and post-test measurements have been carried out. The results obtained are presented in Table 3. 
Table 3. Experimental results for polyurethane foam type C

\begin{tabular}{|l|c|c|c|c|c|c|}
\hline Parameter/Specimen type & C1 & \multicolumn{2}{|c|}{ C2 } & \multicolumn{4}{c|}{ C3 } \\
\hline Impact velocity [m/s] & 8.75 & 8.35 & 6.78 & 7.79 & 8.30 & 8.52 \\
\hline Rebound velocity [m/s] & 1.86 & 2.18 & 1.83 & 1.63 & 1.86 & 1.90 \\
\hline Dissipated energy [J] & 40.57 & 36.06 & 23.65 & 32.20 & 36.31 & 38.28 \\
\hline Dissipated energy [\%] & 95.48 & 93.18 & 92.71 & 95.62 & 94.97 & 95.02 \\
\hline Rebound energy [J] & 1.92 & 2.63 & 1.85 & 1.47 & 1.92 & 2.00 \\
\hline Initial height [mm] & 24.40 & \multicolumn{2}{|c|}{19.80} & & 20.00 \\
\hline Minimal height video measured [mm] & 1.62 & 1.20 & 1.87 & 1.96 & 1.75 & 1.90 \\
\hline Maximum volumetric strain [\%] & 92.50 & 93.50 & 89.60 & 88.80 & 89.90 & 89.00 \\
\hline Post test volumetric strain [\%] & 58.10 & 46.10 & 59.90 & 47.50 & 50.50 & 54.00 \\
\hline Post-test height [mm] & 9.10 & 7.20 & 10.00 & 9.20 & 8.00 & 8.60 \\
\hline Dissipation capacity [J/cm ${ }^{3}$ ] & 1.00 & 1.06 & 0.69 & 0.81 & 0.92 & 0.97 \\
\hline Dissipation capacity [J/g] & 17.19 & 18.02 & 11.82 & 14.50 & 16.35 & 17.24 \\
\hline Maximum force [kN] & 14.37 & $>20.00$ & 8.13 & 10.16 & 13.11 & 13.83 \\
\hline
\end{tabular}

The value of the dissipated energy due to polyurethane foam specimen is given by the difference between the impact and the rebound energy of the projectile.

The values of the chosen impact energies allowed over $95 \%$ volumetric strains well above the densification point occurrence.

For each case, the specific dissipation capacity per volume unit respectively mass unit, was calculated.

For example, for $\mathrm{C} 1$ sample, the dissipation capacity for a volume reduction of $92.5 \%$ is about $1 \mathrm{~J} / \mathrm{cm}^{3}$. The same property expressed in relation to mass indicates a dissipation capacity of $17.19 \mathrm{~J} / \mathrm{g}$.

\section{Conclusions}

The paper addresses polyurethane foam mixed with fly ash ceramic micro powder response to dynamical load.

The tested samples were obtained from plates of different thickness, which presented a limited density variation.

The information regarding the specific stress-volumetric strain that characterize the studied polyurethane foam indicates a high absorption capacity. Also, specific stress vs volumetric strain curves were plotted. Image analysis results are in good correlation with the ones recorded by the force transducer.

For experimental tests in dynamic regime the absorption energy capacity and the rebound energy were calculated. Further mathematical data processing allowed the calculation of specific values.

Due to the extreme loadings the tested samples exhibit plastic remanent deformations. Also, the large difference between the final dimensions and the minimum ones measured during the test, and the measured rebound energies represent evidences of the mechanical hysteresis presence.

\section{References}

1.SHUKLA, A., RAJAPAKSE, Y., HYNES, M.E., Blast Mitigation: Experimental and Numerical Studies, 2014th Edition, Springer; 2014

2. IANNUCCI, L., POPE, D., High velocity impact and armor design, Express Polym. Lett., 5, 2011, $262-272$.

3. BUCUR, F., Contributions to improve protection factor of military vehicles armor - PhD thesis, Military Technical Academy, 2015.

4. ROTARIU, A.-N. DIMA, C., TRANĂ, E. ENACHE, C.,TIMPLARU, F., MATACHE, L.-C., Uninstrumented Measurement Method for Granular Porous Media Blast Mitigation Assessment, Experimental Techniques, 2015.

5. LINUL, E., ŞERBAN, D., VOICONI, T., MARSAVINA, L., SADOWSKI, T., Energy - Absorption and Efficiency Diagrams of Rigid PUR Foam, Key Engineering Materials, 601, 2013, 246-249.

10.4028/www.scientific.net/KEM.601.246. 
6. PRADEL, P., MALAISE, F., DE RESSÉGUIER, T. et al., Dynamic compaction of polyurethane foam: experiments and modelling, Eur. Phys. J. Spec., 227, 2018, 3-16.

7. VOICU, A.D., HADĂR, A., VLĂSCEANU, D., Improving the Mechanical Behavior of a Helicopter Tail Rotor Blade Through the Use of Polyurethane Foams, Rev. Chim., 70(11), 2019, $4123-4127$.

8. GOODS, H.S. Mechanical Properties and Energy Absorption Characteristics of Polyurethane Foam, Sandia National Laboratories, 1997.

9.WITKIEWICZ, W., ZIELIŃSKI, A., Properties of The Polyurethane (Pu) Light Foams, Advances in Materials Science, 6(2), 2006, 35-51.

10. HOFF, G.-F., Shock Absorbing Materials, U.S. Army Waterways Experiment Station, 1967.

11. ROTARIU, A., TRANĂ, E., CIRMACI-MATEI, M.-V., BADEA, S., Static and Dynamic Measurement of Polyurethane Foam Strength and Energy Absorption Capacity, International Journal of Mechanical and Production Engineering (IJMPE), 4(8), 2016, 31-34.

12. CHOU, MI.M., Fly Ash. In: Meyers R.A. Encyclopedia of Sustainability Science and Technology, Springer, New York, NY., 2012.

https://doi.org/10.1007/978-1-4419-0851-3_121

$\overline{\text { Manuscript received: 08.12.2020 }}$ 